\title{
Salivary biochemical assessments to determine smoking cessation under smoking cessation program
}

Daood Umer ( $\sim$ umerdaood@imu.edu.my )

International Medical University https://orcid.org/0000-0002-7631-1628

Mohammed Nadeem Bijle

University of Hong Kong

Syed Sarosh Mahdi

Jinnah Medical and Dental College

Hanan Omar

A T Still University

\section{Sobia Bilal}

International Medical University

Research article

Keywords: amide; disulphide bonds; MMP-8; non-smoker; protein; Raman spectroscopy; saliva; smoker.

Posted Date: August 1st, 2020

DOl: https://doi.org/10.21203/rs.3.rs-41594/v1

License: (9) This work is licensed under a Creative Commons Attribution 4.0 International License. Read Full License 


\section{Abstract}

Background: The study aim was to investigate the potential of salivary biochemical assessments to determine smoking cessation in patients under smoking cessation programs.

Methods: The study validated smoking behavior and degree of nicotine dependence using Fagerström test for nicotine dependence in smokers and non-smokers. Protein components were examined using Raman spectroscopy. Salivary MMP-8 levels were analyzed using Quantikine human total MMP-8 immunoassay-kits. Thiocyanate ( $\left.\mathrm{SCN}^{-}\right)$concentrations, peroxidase and glutathione-peroxidase activities were determined using spectrophotometric methods. Human mononuclear cell line was examined for M1 polarization. The data were analyzed using Fisher's exact test and two-tailed paired t-test at $a=0.05$.

Results: Amide I peak in smoker group was significantly reduced as compared to non-smokers $(p<0.05)$. Sulfhydryl bond, dialkyl disulfides SS-stretch and corresponding disulphide bond at $500-545 \mathrm{~cm}^{-1}$ were significantly increased in smokers $(\mathrm{p}<0.05)$. The $\mathrm{CH}_{2}$ wag showed higher intensity amongst smoker group representing a recoil of carbon atoms. Salivary MMP-8 levels of participants after smoking cessation was significantly lower than smoking salivary levels $(\mathrm{p}<0.05)$. The $\mathrm{SCN}^{-}$and peroxidase concentrations were significantly higher in smoking group whereas an M1 polarization was seen in non-smokers.

Conclusion: Salivary biochemical analysis can aid clinicians to verify smoking cessation in patients under smoking cessation programs.

\section{Background}

Saliva is a multi-constituent fluid which can be collected by non-invasive means and has considerable potential for surveillance of general health through biochemical profiling [1]. It contains several proteins, peptides, matrix metalloproteinases (MMP), antibacterial enzymes, growth factors, and immunoglobulins that have specific functions towards health and disease [2,3]. Saliva sampling has little ethical and consent constraints as opposed to other types of sample collections. The composition of saliva is not as complex as serum and thus, the biochemical parameters can be accurately and rapidly profiled to assess any suggestive disease state [4]. Therefore, salivary biochemical assessments can be a potential marker to discern risk factors that eventually mediates a pathogenic effect.

Smoking is a major risk factor for strokes, heart attacks, cancer and pulmonary diseases. An estimated 5.4 million deaths were reported by World Health Organization in 2004 and 100 million deaths during the 20th century, due to smoking [5]. The nicotine present within cigarettes is known to metabolize several biochemical components in saliva including proteins, mucins, and MMPs [6-8]. The nicotine-mediated metabolites can be a potential biochemical marker to identify the smoking habits extent, addiction and cessation. Thus, there is a need to identify the biochemical parameters that can distinguish between smoking patterns. 
Raman spectroscopy analyses biological tissues and fluids at molecular level while ciphering detailed information for diagnosis $[9,10]$. The method is rapid while requires only a small quantity of biological fluids for analysis. The approach is dependent on vibration transitions due to inelastic scattering of monochromatic light at infrared ranges. No studies have utilized the technique to identify smokingrelated changes. Similarly, salivary MMPs and significant metabolites like thiocyanate $\left(\mathrm{SCN}^{-}\right)$and peroxidase have not been investigated to identify changes in patients attempting smoking cessation under a smoking cessation program. Thus, the biochemical parameters and the technique (Raman spectroscopy) can be further investigated to identify its potential as a smoking cessation marker.

Seventy percent of the smokers express a voluntary desire to quit smoking, of which $80 \%$ return to smoking within the first month. A $<20 \%$ quit smoking for 6 months with $3 \%$ remaining abstinent for more than a year [11]. Several health universities have initiated smoking cessation programs to help people quit smoking while routinely monitor smoking status and outcomes of their service users. The program participants are made to understand oral and general health hazards of tobacco which motivates them to quit smoking [12]. The Russell standards for smoking cessation suggested that smoking cessation should be biochemically validated through studies to exhibit variables that can verify smoking cessation in program participants [13]. However, no studies in the literature could be identified that examine the potential of salivary biochemical parameters to determine smoking cessation in participants under smoking cessation program. Thus, the present study aimed at investigating the potential of salivary biochemical assessments to determine smoking cessation in patients under smoking cessation programs. The tested null hypothesis in the present study was that there is no difference in the salivary biochemical components of the smokers and non-smokers or smoker who have quit smoking.

\section{Methods}

\subsection{Study design, setting, and sampling}

Patients enrolled in smoking cessation program were included in the study with no significant past medical history. The treatment provided under the program included an assessment of patient's current commitment, readiness and ability to quit smoking throughout the quitting process, co-validated smoking behavior and patient's degree of nicotine dependence using validated tools such as the Fagerström test for Nicotine Dependence. The program included behavioral support to assist the patient to set a quit date and support the patient to exercise self-control. All patients were given the opportunity to provide feedback through a pre-designed patient satisfaction questionnaire. Regular audits were also performed to monitor the program performance.

Through non-probability purposive sampling five patients per group $(n=5)$ were selected based on voluntary participation after explaining the study design and thoroughly obtaining consent from the patients.

\subsection{Inclusion and exclusion criteria}


The inclusion and exclusion criteria for the study was as follows:

Inclusion criteria:

- Patients using smoked tobacco products: including cigarettes, cigars, and pipes.

- A standard definition of tobacco use in adolescents is any use in the past 30 days. But the standard patients will include patients that have been smoking for $\geq 3$ years at least 10 cigarettes/day.

- Humans, all races, ethnicities, cultural groups.

- Adults with age range between 21-50 years.

- Patients with apparently healthy medical history.

Exclusion criteria:

- Patients with compromised medical history.

- Adults under the age of 21 years.

- Patients having less than 10 cigarettes/day.

- Patients not using tobacco, including cigarettes, cigars, and pipes.

\subsection{Saliva collection}

The saliva was collected in both stimulated and unstimulated conditions. For stimulated conditions, subjects chewed a $5 \mathrm{gms}$ piece of paraffin wax for 5 minutes before saliva collection. While for unstimulated conditions, it was collected in the resting phase of the patient. After saliva collection, it was maintained on ice and immediately centrifuged within $1 \mathrm{~h}$ of collection at around $12000 \times \mathrm{g}$ for 30 min to remove debris. The samples were subjected to $70 \%$ ethanol. This was done to precipitate protein samples from the saliva.

\subsection{Raman micro-spectroscopy}

The saliva was transferred in a germproof medicine glass and later put into sterile test tube by a disposable syringe used separately for each specimen $(5 \mathrm{ml})$. The tubes were placed in a portable refrigerator (ETS compressor portable freezer; Dataran Mestika, Taman Mestika, 56100 Kuala Lumpur, Malaysia) under $4^{0} \mathrm{C}$ and moved to the venue of Raman investigation. The period of transportation did not exceed 30 minutes, which is well below the time to guarantee preservation of biological properties of the specimens [14]. All Raman analysis were carried out using Raman microscope (LabRam Horiba JobinYvon) at Nanocat Research Center, UM, Kuala Lumpur having Rayleigh rejection filter and a cooled charged-couple device detector. The spot size of the excitation beam was $1.1 \mu \mathrm{m}$ with a collimation made by $100 \mu \mathrm{m}$ pinhole. The diode laser (Coherent, CUBE) had an excitation wavelength of $785 \mathrm{~nm}$ with incident laser power on the sample upto $10 \mathrm{~mW}$ at $\times 20$ objective. The exposure time was $20 \mathrm{~s}$ with 5 accumulations focused on the salivary specimen (placed inside by help of portion of a wet pellet placed between two glass slides before drying as a thin film in a container filled with $\mathrm{N}_{2}$ gas) by using a 
computer-controlled $x-y-z$ stage to induce the Raman scattering with effect spectral acquisition of 600 lines/mm grafting. The scans were acquired obtained over the spectral regions from $1700 \mathrm{~cm}^{-1}$ to $3200 \mathrm{~cm}^{-1}$ (intensities of the amide I peak at $1740-1550 \mathrm{~cm}^{-1}$, the S-S stretch at $600-470 \mathrm{~cm}^{-1}$, and SH at $2,480-2,620 \mathrm{~cm}^{-1}$ will be measured). Centroid cluster measurements were examined via three measurements at the same regions $\left(1740-1550 \mathrm{~cm}^{-1}\right.$, and $1248-1273 \mathrm{~cm}^{-1}$, the S-S stretch at $600-$ $470 \mathrm{~cm}^{-1}$ and $\mathrm{SH}$ at $2480-2620 \mathrm{~cm}^{-1}$ ). The measurements were done two times for each specimen to confirm the reproducibility of the technique. The intensity peaks at $1667 \mathrm{~cm}^{-1}$ and $1246 \mathrm{~cm}^{-1}$, representative of the organic content by Amide I and III respectively, were taken as standards, to compare the readings and analyze the changes between smokers and non-smokers. The raw spectra were imported into MATLAB version (Math Works, Inc., Natick, MA) and baseline corrected by polynomial order. This procedure was repeated with each subset reaching the validation to ensure the model was fit for interpretation.

\subsection{MMP-8 analysis}

Around, $2 \mathrm{ml}$ of saliva was collected and placed in a sterile saliva collecting tube according to the method mentioned in a previous paper [15]. The samples were initially stored at $-75^{\circ} \mathrm{C}$. Salivary MMP-8 levels were analyzed using Quantikine human total MMP-8 immunoassay kits (R and D Systems, Inc., USA) by ELISA (Quantikine Human Total MMP-8 Immunnoassay; Catalog Number DMP800). Using a correction wavelength set at $540-570 \mathrm{~nm}$, the absorbance was read at $\mathrm{OD}_{450 \mathrm{~nm}}$ using a spectrophotometer.

\subsection{Antioxidant enzymes and thiocyanate}

The thiocyanate $\left(\mathrm{SCN}^{-}\right)$levels were determined using spectrophotometric method where $1 \mathrm{ml}$ of tricholoroacetic acid $(20 \% \mathrm{~V} / \mathrm{v}$.) solution was mixed with diluted saliva sample $(2 \mathrm{ml})$ to further precipitate the proteins. After performing centrifugation $(4000 \times \mathrm{g}$ at $10 \mathrm{~min}$ ), $1 \mathrm{ml}$ of ferric nitrate-nitric acid reagent was added to a $2 \mathrm{ml}$ supernatant. The absorbance was measured at $\mathrm{OD}_{460 \mathrm{~nm}}$ using a standard protein assay kit (BIO-RAD, Hercules, CA, USA). The standard curve was obtained using serum albumin.

The peroxidase (Px) activity was measured by mixing $1 \mathrm{ml}$ phosphate buffer ( $\mathrm{pH} 7.0), 1 \mathrm{ml}$ guaiacol solution, and $0.1 \mathrm{ml}$ of a saliva sample. Later a stock solution of $1 \mathrm{ml} \mathrm{H}_{2} \mathrm{O}_{2}$ was added and absorbance measured at $\mathrm{OD}_{470 \mathrm{~nm}}$. Glutathione-peroxidase (GSH-Px) levels were measured using RADSOD and RANSEL (Randox Laboratory Ltd., Ardmore, UK). The well of microplates was covered with monoclonal antibodies specific to GSH-Px. The amount of GSH-Px was quantified by the enzymatic hydrolysis of pnitrophenyl phosphate and measured at $\mathrm{OD}_{405 \mathrm{~nm}}$ in a microplate reader using a spectrophotometer.

\subsection{Macrophages}

Human peripheral blood mononuclear cell line, SC (CRL-9855 \#LOT: 61834527) was obtained from American Tissue Type Culture (ATCC). After maintaining $2 \times 10^{5}$ cell concentration in the flask, cells were counted using Iscove's Modified Dulbecco's Media (IMDM; ATCC, Lot:63331110-Manassas/VA). $1 \times 10^{6}$ cells/ml were cultured supplemented with $10 \%$ FBS, 0.05 mM 2-mercaptoethanol, 0.1 mM hypoxanthine 
and $0.016 \mathrm{mM}$ thymidine. The macrophage cells were expanded in specific growth mediums and seeded into 6-well plates at concentration of $1 \times 10^{5} \mathrm{cells} / \mathrm{cm}^{2}$.

For the cell exposure, saliva was sampled on the day of cell exposure. After $6 \mathrm{~h}$ (without removing existing well contents), lipopolysaccharide (LPS-PG [Lipopolysaccharide from Porphyromonas Gingivalis] Ultrapure/Porphyromonas gingivalis-TLR4 ligand; $0.1 \mu \mathrm{g} / \mathrm{ml}$ ) was placed over the macrophage cells added with interferon gamma (IFN $\gamma-; 20 \mathrm{ng} / \mathrm{ml}$ ), respectively for M1 polarization. Dose response of saliva $(0.05 ; 0.5 ; 5 \%$ for $24 \mathrm{~h})$ was done inside 12 -well plates with macrophage cells entrapped in fibrin matrix with $300 \mu$ of $1 \%$ plasminogen-free fibrinogen.

\subsection{Statistical analysis}

The data were analyzed using SPSS software v. 20 (SPSS IBM statistics, Chicago, USA). All Raman spectroscopy measurements were tested using Fisher's exact probability test. The MMP-8, antioxidant enzymes, and thiocyanate levels were analyzed using two-tailed paired t-test. For all statistical tests, the significance levels was set at $a=0.05$.

\section{Results}

\subsection{Raman spectroscopy}

Figure 1 shows Raman spectra of S-S stretch and Amide I derived from disulphide bonds of saliva. S-S stretch bands and corresponding Amide I, showed significant changes between the salivary samples while smoking and after quitting $(p<0.05)$. The Amide I peak in smoker's saliva (blue line) was significantly reduced as compared to non-smokers. The sulfhydryl bond, SS-stretch and the corresponding disulphide bond at $500-545 \mathrm{~cm}^{-1}$ were significantly increased in smoking saliva $(\mathrm{p}<$ 0.05). As it can be seen in Fig. 1, the spectra of smoker's saliva are different from the spectra of saliva after quitting. The two intense peaks at $2440 \mathrm{~cm}^{-1}$, and $500 \mathrm{~cm}^{-1}$ show marked changes in terms of reduction in intensities and are used as a measure of oxidation. The disulphide bridges are significantly higher in the smokers' saliva. Moreover, the peak position at $1310 \mathrm{~cm}^{-1}$ in the non-smokers saliva proteins seemingly had shifted to $1318 \mathrm{~cm}^{-1}$ in smoker's saliva proteins having lower intensity.

For the measurements of glycopeptides via Raman spectroscopy, the Amide I region shown in Fig. 1 was centred around $1665-1680 \mathrm{~cm}^{-1}$. The major peak in the Amide I region of is centred and assigned to $\beta$ sheet which may be due to backbone, side chain or carbohydrate structures also, but this is not yet known. This investigation by Raman spectroscopy reported enabled peak assignment within the study and may also provide information about the structural characteristics of mucins within the saliva of smokers and non-smokers. The changes are seen amongst the peaks in terms of their glycosylation and secondary structure (Table 1).

Table 1: MMP-8 levels of smoking and after quitting participants. Paired two-tailed t-test to examine the effects of salivary MMP-8 levels ( $\mathrm{p}<0.05$ is significant). 


\begin{tabular}{|c|c|c|c|c|}
\hline Parameters & Values & $\begin{array}{l}\text { Group Smoking } \\
\text { MMP-8 (ng/ml) }\end{array}$ & $\begin{array}{l}\text { Group After Quitting } \\
\text { MMP-8 (ng/ml) }\end{array}$ & p-value \\
\hline $\begin{array}{l}\text { Age }(m v \pm s d) \\
\text { Gender }\end{array}$ & $37.8 \pm 7.8$ & \multirow{3}{*}{$99.11 \pm 17.09$ B } & \multirow{3}{*}{$56.12 \pm 23.11 \mathrm{~A}$} & \multirow{3}{*}{$\leq 0.05$} \\
\hline Male & $5(50 \%)$ & & & \\
\hline Female & $5(50 \%)$ & & & \\
\hline
\end{tabular}

Figure 2 represents the Raman spectra recorded in the region between 1365 and $1715 \mathrm{~cm}^{-1}$. The peaks at $1667 \mathrm{~cm}^{-1}$ and $1446 \mathrm{~cm}^{-1}$ are associated with organic components and well represented. The Amide I shows a drop in smoker's saliva (blue line) as compared to the non-smokers saliva representing $C=0$ (carbonyl) stretch of the amide group, coupled with the in-plane $\mathrm{N}-\mathrm{H}$ bending and $\mathrm{C}-\mathrm{N}$ stretching vibration from the polypeptide chain in the protein and is hardly affected in the non-smokers saliva. On the contrary, the $\mathrm{CH}_{2}$ wag showed higher intensity amongst smoker's saliva representing a recoil of the $\mathrm{C}$ atoms. The peaks at 1653 for smoker's saliva indicate polypeptide backbone of a protein due to amide and aromatic ring breathing. The mucin matrices are known to be observed by Raman shifts of the $\mathrm{CH}$ stretching peak at $1444 \mathrm{~cm}^{-1}$. These peaks are inherent to Raman spectra of saliva. The peak at $2067 \mathrm{~cm}-1$ is very unique to saliva and likely caused by thiocyanate. The peak intensities are more significant $(p<0.05)$ as compared to spectrum of saliva from patients who had quit smoking (Fig. 3 ). Smoking produced more significant changes in the peaks and showed higher intensities $(p<0.05)$.

\subsection{Salivary MMP-8}

The salivary MMP-8 levels (Table 2) of participants after quitting smoking was significantly lower when compared to the salivary levels while smoking $(p<0.05)$. The smoking factor had a significant effect on the MMP-8 levels and the interaction of the two groups was also significant $(p<0.05)$.

Table 2: Peaks identified by band de-convolution of the Amide I region in Raman spectra of smokers and nonsmokers saliva.

\begin{tabular}{|c|c|c|c|c|c|c|c|c|}
\hline \multicolumn{9}{|c|}{ Wavenumber $\left(\mathrm{cm}^{-1}\right)$} \\
\hline & \multicolumn{2}{|c|}{$<1630$} & \multicolumn{2}{|c|}{$1630-1650$} & \multicolumn{2}{|c|}{ 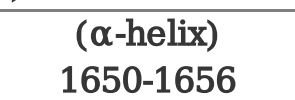 } & \multicolumn{2}{|c|}{$\begin{array}{c}\text { ( } \beta \text {-sheet) } \\
1665-1680\end{array}$} \\
\hline Sample & Peak & Area (\%) & Peak & Area (\%) & Peak & Area (\%) & Peak & Area (\%) \\
\hline Control & 1610 & 3 & 1640 & 1 & 1655 & 27 & 1671 & 18 \\
\hline Smoking & 1625 & 7 & 1671 & 15 & 1667 & 31 & 1678 & 33 \\
\hline Non-smoking & 1615 & 4 & 1651 & 8 & 1654 & 14 & 1661 & 10 \\
\hline
\end{tabular}

\subsection{Antioxidant enzymes and thiocyanate}

Antioxidant values are summarised in Table 3. The $\mathrm{SCN}^{-}$and peroxidase levels were significantly higher in smokers' group $(p<0.05)$; whereas GSH-Px levels were significantly higher in the non-smoking group ( $p$ $<0.05)$. No significant correlation was found between $\mathrm{SCN}^{-}$and $\mathrm{GSH}-\mathrm{x}(\mu \mathrm{g} / \mathrm{mg})$ activities amongst 
smokers and non-smokers groups ( $p>0.05$ ) with significant differences between $\mathrm{SCN}^{-}$and peroxidase activities between the groups $(p<0.05)$.

Table 3: Mean values representing the antioxidant enzymes and $\mathrm{SCN}^{-}$along with correlation.

\begin{tabular}{cccccc}
\hline & Non-smokers & Smokers & p-value & $\mathrm{r}$ & $\mathrm{p}$-value \\
\hline $\mathrm{SCN}^{-}$ & $11.2 \pm 5.6$ & $34.5 \pm 17.88$ & 0.04 & 0.29 & 0.071 \\
\hline $\mathrm{Px}(\mathrm{U} / \mathrm{mg})$ & $0.05 \pm 0.09$ & $0.11 \pm 0.07$ & 0.003 & 0.41 & 0.001 \\
\hline $\mathrm{GSH}-\mathrm{Px}(\mathrm{\mu g} / \mathrm{mg})$ & $4.1 \pm 1.8$ & $1.9 \pm 2.7$ & 0.000 & 0.07 & 0.062 \\
\hline
\end{tabular}

\subsection{Macrophages}

The non-smokers groups saliva when exposed for $24 \mathrm{~h}$ increased IL6 and IL 12 response indicating an M1 type polarization of the macrophages. The levels were significantly different when compared to the smoker's saliva for the human peripheral blood mononuclear cell line as the respective activity was lost (Fig. 4). The data represented salivary activity of smokers which is sensitive to M1 phenotype.

\section{Discussion}

Tobacco addiction and smoking are a chronic, relapsing condition and it is difficult to achieve long term abstinence for smokers [16]. Smoking becomes a highly conditioned behaviour, that can trigger relapse while attempts are made for quitting. In our study, it was demonstrated that recruiting patients for tobacco cessation and participation in a research study on tobacco control is a successful strategy. This further paved way for encouraging smokers to participate and stay engaged in the tobacco preventive and cessation programme. This study in particular is considered novel in measurement and analysis of salivary samples in a time period as minimum as 3 months after baseline with biochemical verification measures. The findings of the spectroscopic and MMP-8 changes to other cessation studies maybe limited. No other studies were found in the literature with these two findings for comparison amongst patients and participants reporting to the tobacco cessation clinics.

By using Raman spectroscopy, we confirmed the increased S-S stretch band from protein disulphide bonds in saliva when subjects were smoking. Smokers saliva have altered multimolecular mucin complex as previously reported verifying the detection of disulphide residues in our samples $[17,18]$. There is an oxidant/antioxidant imbalance of due to a significant decrease of GSH-Px activity in smoker's saliva [19]. From our results, the increase in protein oxidation in smoker's saliva, and a significant reduction seen amongst saliva of non-smoking status, we believe that enzymatic modifications were minimal, and the tobacco cessation protocols had brought about a significant change in the patient's biochemical profile. 
There was a significant increase in the intensity of disulphide bond at $500-545 \mathrm{~cm}^{-1}$ suggestive of change. Some differences between the two groups still existed, and the difference spectrum made them apparent. The characteristic vibrational modes are mainly dominated by the protein constituents of the salivary samples. The vibrational band analysis and assignments are done keeping in mind the group frequencies of the various analytes present in the sample [20].

Figure 1 shows the corresponding difference spectra of the different salivary groups revealing the significant spectral changes such as peak intensities, shoulder bands and specific spectral ranges. The changes can be related certain vibrational bonds and clearly suggest that the Amide I peak in smoker's saliva (blue line) was significantly reduced as compared to non-smokers. These results suggest that there is a remarkable increase in the percentage of biochemical constituents among the saliva protein groups, indicating the diagnostic potential of Raman for saliva protein identification of the smoker's saliva. The reduction in Amide I band is a staggering difference when compared to the saliva in non-smoking status where the Amide I can gradually increase. These changes along with other spectra differences seen provide an understanding that there is less multimolecular mucin complex in the saliva of smokers. Although Amide I band decreases, the levels of disulphide bonds are different between smoker's saliva and non-smokers one. Further, in order to quantify the variations between smokers and non-smokers saliva, there was an increase in the $\mathrm{CH}_{2}$ deformation vibration in smoker's saliva. In addition, in our parallel study, X-ray fluorescence analysis showed different chemical elements in the saliva of smokers and non-smokers with biggest discrepancies found at $\mathrm{Cr}$. Mn and Ca components in smoker's saliva (data not shown).

MMP-8 has been considered a key biomarker and major collagenolytic metalloproteinase in oral fluids and its elevated levels have been reported to have been seen amongst periodontitis patients. In this particular study, the quantitative direct assesment of MMP-8 showed that the levels were significantly increased and lowered in smoking and non-smoking salivary specimens respectively $(p<0.05)$. This is primarily due to the fact that there is impairment of granulocyte function which is receptive to microbial changes too delivering excessive elastase, proteases and MMP-8 [21]. Therefore, the second null hypothesis that smoking may not have any effect on MMP-8 levels has to be rejected. It is well known that reactive oxygen species may significantly lower proteolytic activity and MMP-8 within the salivary specimens of smokers by inactivating latent-pro MMPs and MMP-8 fragment [22]. The strong association between smoking and periodontitis is also well established and might be reinforced by this point. Therefore, smoking may interfere with the levels of MMP-8 and should be considered when using saliva for diagnosis.

The spectral components found as a result of Raman are complex and the assignments are based on known salivary composition and literature [23]. Although the concertation of GSH-Px and Px levels were determined, it does not always relate to enzymatic activity within the saliva. The $\mathrm{SCN}^{-}$levels were significantly high $(\mathrm{p}<0.05)$ and a significant correlation between $\mathrm{SCN}$ - and $\mathrm{Px}(\mathrm{U} / \mathrm{mg})$ was found. This is a clear indication that the oxidative stress as a result of smoking increased the levels of oxidases. Px levels were remarkably lower in smokers is supported by the fact that Px serves as a protective defense 
mechanism where $\mathrm{H}_{2} \mathrm{O}_{2}$ is converted into molecular oxygen and gets detoxified by the cigarette smoke [24]. It is also possible that GSH-Px levels were affected by smoking levels. The macrophage result was a clear indication that non-smokers saliva provoked the polarization toward the proinflammatory M1 phenotype. These findings are consistent with the fact that saliva also invokes a proinflammatory response in oral fibroblasts [25]. CD14 is present in human saliva mainly on the surface of monocytes and macrophages [26]. However, M1 polarization by saliva likely occurs independently of soluble CD14. It is also known that the lipopolysaccharide that can induce M1 polarization [27]. It is reasonably safe to speculate that the salivary endotoxins can increase the expression of IL 12 and IL 6 by macrophages and causing them to develop a proinflammatory M1 phenotype.

A comprehensive effort to reduce tobacco-related disparities includes clinical cessation interventions, accessibility, social acceptability, as well as population-level measures to reduce the appeal of tobacco [28]. In our study, one of the limitations was a relatively short follow-up period of three months. It is known that smoking habits tend to come back within this time period [29]. There was no dropping out of participants and were quite motivated. Further efforts are being made to expand the program and improve its effectiveness.

\section{Conclusion}

Based on the present study results, it can be concluded that the salivary biochemical analysis can aid clinicians to verify smoking cessation in patients under smoking cessation programs.

\section{List Of Abbreviations}

ATCC - American Tissue Type Culture

GSH-Px - Glutathione peroxidase

MMP - Matrix metalloproteinases

Px - Peroxidase

$\mathrm{SCN}^{-}-$Thiocyanate

\section{Declarations}

\section{Ethics approval and consent to participate}

Ethical approval was obtained prior to the study initiation (IRB approval \#391/2017, IMU Joint Committee on Research Ethics). The participants were informed of the study design and consented to participate in the study. 
Not applicable

\section{Availability of data and materials}

The datasets used and/or analyzed during the current study are available from the corresponding author on reasonable request.

\section{Competing interests}

The authors declare that they have no competing interests.

\section{Funding}

The research was funded by International Medical University grant \#391/2017. The funders have no role in this research.

\section{Authors' contributions}

Conceptualization, U.D. and M.N.B.; methodology, S.B and U.D..; investigation, U.D., H.O., and S.B.; resources, U.D.; writing-original draft preparation, M.N.B.; writing-review and editing, M.N.B., U.D., S.S.M, H.O., and S.B..; funding, U.D. All authors have read and approved the final manuscript.

\section{Acknowledgements}

Not applicable

\section{References}

1. Streckfus CF, Dubinsky WP. Proteomic analysis of saliva for cancer diagnosis. Expert Rev Proteomics. 2007;4:329-32.

2. Slomiany BL, Murty VLN, Piotrowski J, Slomiany A. Salivary mucins in oral mucosal defense. Gen Pharmacol. 1996;27:761-71.

3. Lee Y, Wong D. Saliva: an emerging biofluid for early detection of diseases. Am J Dent. 2009;22:2418.

4. Griffiths HR, Møller L, Bartosz G, Bast A, Bertoni-Freddari C, Collins A, et al. Biomarkers. Mol Aspects Med. 2002;23:101-208.

5. WHO Library Cataloguing. World Health Organization, Switzerland. 2008. www.who.int/evidence/bod. Accessed 29 Oct 2008.

6. Kirkham S, Sheehan JK, Knight D, Richardson PS, Thornton DJ. Heterogeneity of airways mucus: Variations in the amounts and glycoforms of the major oligomeric mucins MUC5AC and MUC5B. Biochem J. 2002;361:537-46. 
7. Stadtman ER, Levine RL. Free radical-mediated oxidation of free amino acids and amino acid residues in proteins. Amino Acids. 2003;25:207-18.

8. Sorsa T, Nwhator S, Rathnayake N. Active matrix metalloproteinase-8 - contributor to periodontitis and a missing link between genetics, dentistry and medicine. In: Bostanci N, Belibasakis G, editors. Pathogenesis of periodontal diseases - biological concept for clinicians. Heidelberg, Germany: Springer Nature Verlag; 2017. p. 51-7.

9. Bai H, Chen P, Tang GQ, Lin L, Fang H, Mu GG, et al. Relations between reactive oxygen species and Raman spectral variations of human umbilical cord mesenchymal stem cells with different viability. Laser Phys. 2011;21:1122-9.

10. Chen P, Tian Q, Baek SJ, Shang XL, Park A, Liu ZC, et al. Laser Raman detection of platelet as a noninvasive approach for early and differential diagnosis of Alzheimer's disease. Laser Phys Lett. 2011;8:547-52.

11. U.S. Department of Health and Human Services. The health consequences of smoking -50 years of progress: a report of the surgeon general. U.S. Department of Health and Human Services, Centers for Disease Control and Prevention, National Center for Chronic D. Washington D.C., USA; 2014.

12. Clinical Practice Guidelines on treatment of Tobacco use and dependence. Ministry of Health Malaysia. Kuala Lumpur, Malaysia; 2020.

13. Schuck K, Otten R, Kleinjan M, Bricker JB, Engels RCME. Predictors of cessation treatment outcome and treatment moderators among smoking parents receiving quitline counselling or self-help material. Prev Med (Baltim). 2014;69:126-31. doi:10.1016/j.ypmed.2014.09.014.

14. Chiappin S, Antonelli G, Gatti R, De Palo EF. Saliva specimen: A new laboratory tool for diagnostic and basic investigation. Clin Chim Acta. 2007;383:30-40.

15. Navazesh M. Methods for Collecting Saliva. Ann N Y Acad Sci. 1993.

16. Benowitz NL. Nicotine addiction. N Engl J Med. 2010;362:2295.

17. Denny PC, Denny PA, Klauser DK, Hong SH, Navazesh M, Tabak LA. Age-related Changes in Mucins from Human Whole Saliva. J Dent Res. 1991;70:1320-7.

18. Iontcheva I, Oppenheim FG, Troxler RF. Human salivary mucin MG1 selectively forms heterotypic complexes with amylase, proline-rich proteins, statherin, and histatins. J Dent Res. 1997;76:734-43.

19. Brock GR, Butterworth CJ, Matthews JB, Chapple ILC. Local and systemic total antioxidant capacity in periodontitis and health. J Clin Periodontol. 2004;31:515-21.

20. Déléris G, Petibois C. Applications of FT-IR spectrometry to plasma contents analysis and monitoring. Vib Spectrosc. 2003;32 1 SPEC.:129-36.

21. Bergström J, Preber H. Tobacco Use as a Risk Factor. J Periodontol. 1994;65:545-50.

22. Haber J, Wattles J. Evidence for cigarette smoking as a major risk factor for periodontitis. J Periodontol. 1993; Iddm:16-23. http://www.joponline.org/doi/abs/10.1902/jop.1993.64.1.16.

23. Tenovuo J. Antimicrobial agents in saliva - Protection for the whole body. J Dent Res. 2002;81:8079. 
24. Kanehira T, Shibata K, Kashiwazaki H, Inoue N, Morita M. Comparison of antioxidant enzymes in saliva of elderly smokers and non-smokers. Gerodontology. 2006;23:38-42.

25. Cvikl B, Lussi A, Moritz A, Sawada K, Gruber R. Differential inflammatory response of dental pulp explants and fibroblasts to saliva. Int Endod J. 2016;49:655-62.

26. Haziot A, Chen S, Ferrero E, Low MG, Silber R, Goyert SM. The monocyte differentiation antigen, $\mathrm{CD} 14$, is anchored to the cell membrane by a phosphatidylinositol linkage. J Immunol. 1988;141:547-52.

27. Mosser DM, Edwards JP. Exploring the full spectrum of macrophage activation. Nat Rev Immunol. 2008;8:958-69. doi:10.1038/nri2448.

28. Prochaska JJ, Das S, Young-Wolff KC. Smoking, Mental Illness, and Public Health. Annu Rev Public Health. 2017;38:165-85.

29. Lally P, Van Jaarsveld CH, Potts HW, Wardle J. How are habits formed: Modelling habit formation in the real world. Eur J Soc Psychol. 2010;40:625-34.

\section{Figures}

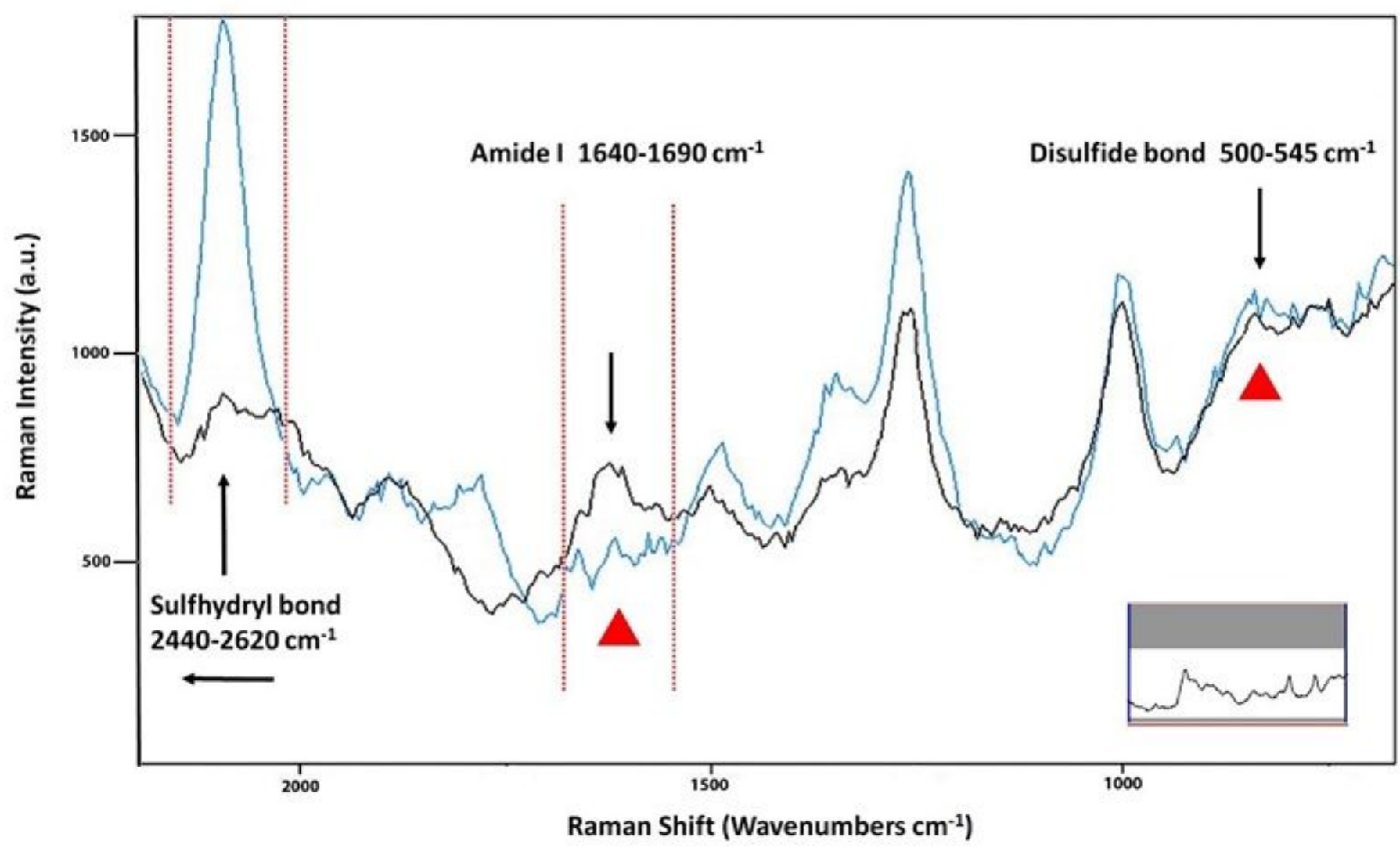

Figure 1

Raman spectra of S-S stretch and amide I derived from disulphide bonds of saliva. The black line corresponds to saliva of patients who had quit smoking against the blue line, of same patients who were 
smoking. S-S stretch bands and corresponding, -SS-/protein ratio (red dotted line; arrow), was significantly higher in the smokers' saliva than in all others $(p<0.05)$. The Amide I peak in smoker's saliva (blue line) was significantly reduced as compared to non-smokers.

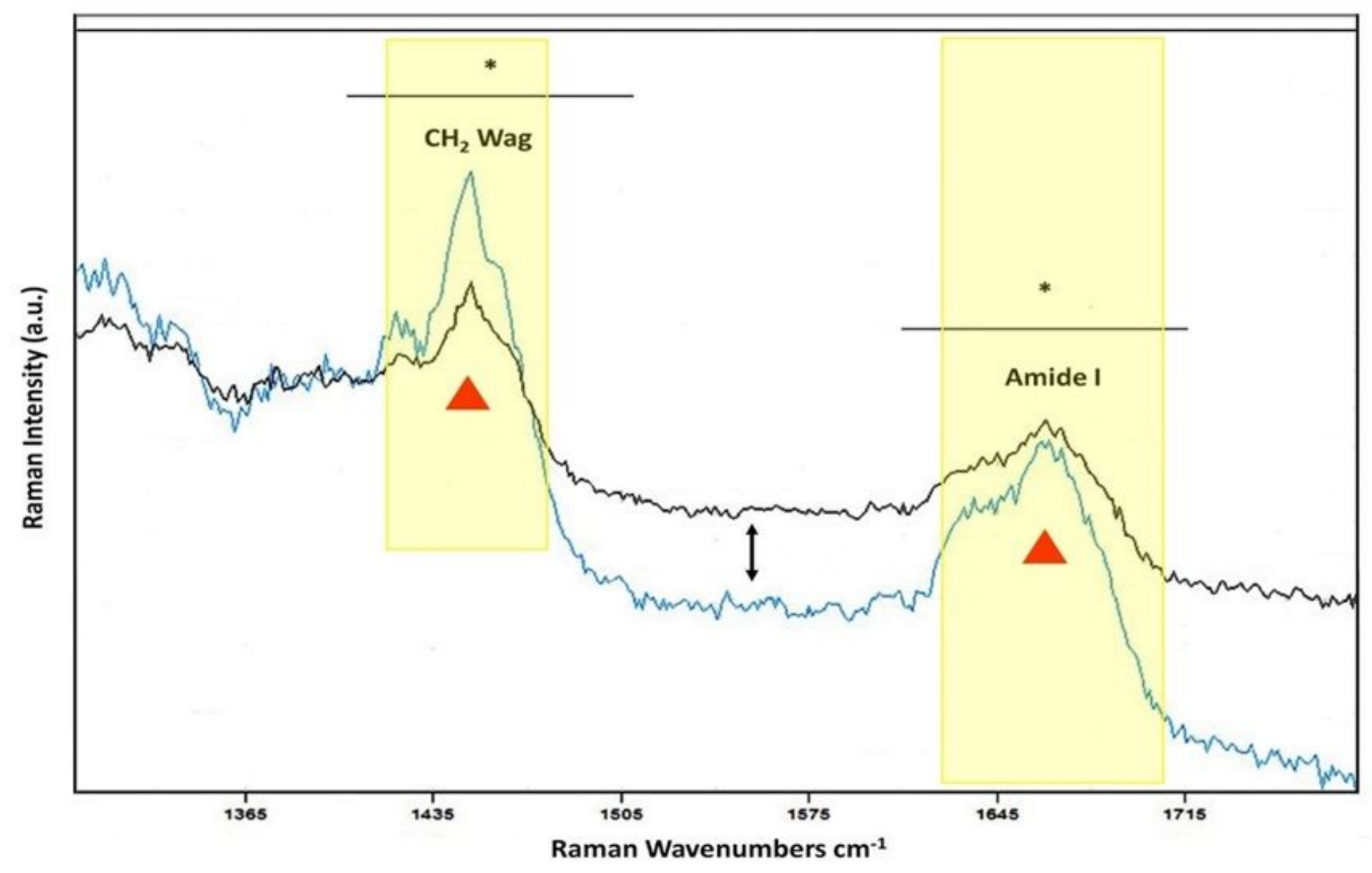

Figure 2

Representative Raman spectra recorded in the region between 1365 and $1715 \mathrm{~cm}-1$. The peaks at 1667 $\mathrm{cm}^{-1}$ and $1446 \mathrm{~cm}-1$ are associated with organic components and well represented. The Amide I shows a drop in smoker's saliva (blue line) as compared to the non-smokers saliva representing $C=0$ (carbonyl) stretch of the amide group, coupled with the in-plane $\mathrm{N}-\mathrm{H}$ bending and $\mathrm{C}-\mathrm{N}$ stretching vibration from the polypeptide chain in the protein and is hardly affected in the non-smokers saliva. On the contrary, the $\mathrm{CH} 2$ wag showed higher intensity amongst smoker's saliva. 


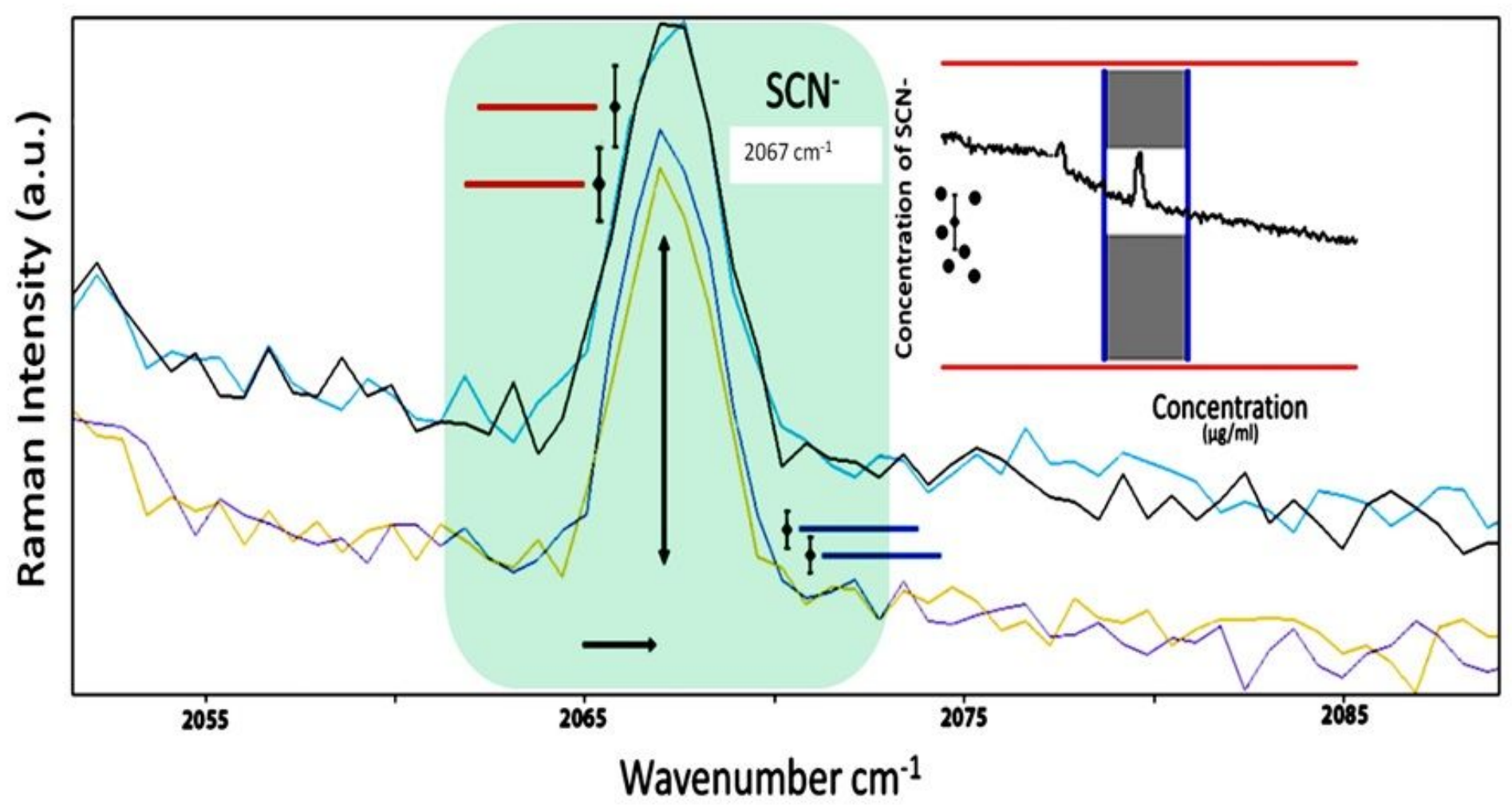

Figure 3

The selected range of Raman spectra of smokers and non-smokers saliva where the peaks at $2065 \mathrm{~cm}-1$ $2067 \mathrm{~cm}-1$ is unique to saliva likely caused by thiocyanate. 


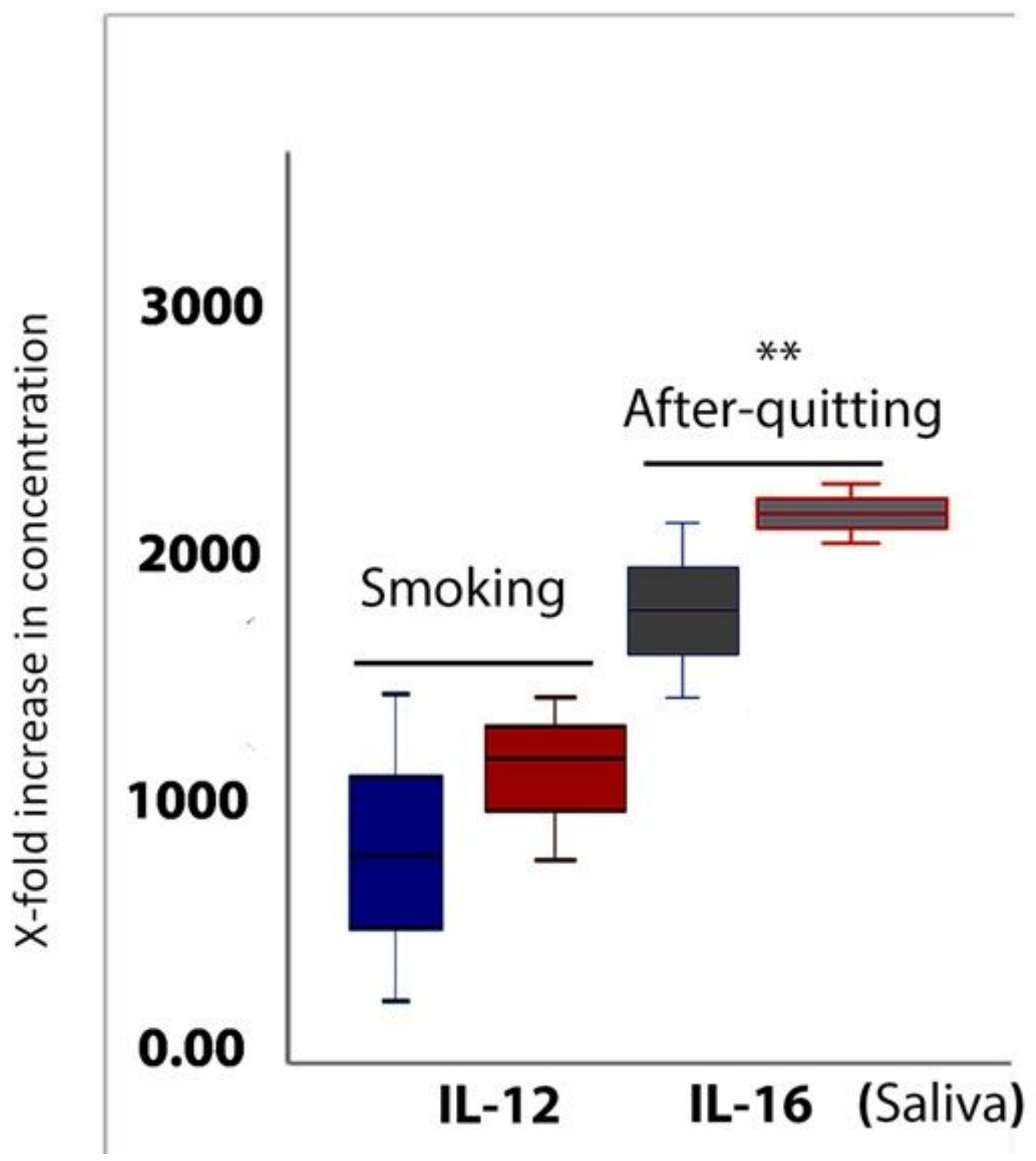

Figure 4

Primary exposure of human peripheral blood mononuclear cell line, SC (CRL-9855) for M1 marker in smoker's and after quitting smoke saliva. The phenotype changes exhibited strong response of M1 proinflammatory against IL12 and IL16 markers in smoker's saliva $(p<0.05)$. 